Results During the initial 4 week period, 24 cards were received and during the period of re-audit, 28 cards were received. This compared with 1 letter of feedback every 4 weeks prior to introduction of the card. 94\% of feedback was in the most satisfied category. Written feedback has been instrumental in structuring and planning of service delivery.

Conclusions The introduction of feedback card led to significant increase in written feedback and helped in re-shaping delivery of care by working with patients. Ongoing use of the feedback card will ensure continued restructuring of the service and review of training needs taking into account patients perspectives and placing patients at the heart of delivery of safe, effective care.

\section{PO-0962 DIAGNOSTICS AND WAYS OF PREVENTIVE MAINTENANCE OF A SYNDROME OF PEDAGOGICAL VIOLENCE V. GANUZIN THE YAROSLAVL STATE MEDICAL ACADEMY, YAROSLAVL, RUSSIA}

V Ganuzin. Polyclinic Pediatrics Department, State Medical Academy, Yaroslav, Russia

10.1136/archdischild-2014-307384.1581

We offer the term - a syndrome of pedagogical violence - which designates occurrence of a complex of deviations in a state of health of schoolchildren under the influence of inadequate pedagogical methods, actions and curriculums.

Classification of a syndrome of pedagogical violence (V. Ganuzin, 2011):

1. A syndrome of the legitimate (legalised) pedagogical violence.

2. A syndrome of administrative pedagogical violence.

3. A syndrome of authoritative pedagogical violence.

The express method has been developed for revealing of a syndrome of authoritative pedagogical violence by means of the questionnaire. By the given technique we spend questioning 220 students, trained before receipt in academy at comprehensive schools of various regions of Russia.

According to questioned, 58,6\% of students marked the presence of conflicts with the teachers during school training; 51,8\% - were afraid of the teachers; $35,1 \%$ - were exposed to humiliation by teachers; $75,7 \%$ were insult by the teachers.

According to poll data, such mutual relations worsen the pupil's health. Thus, at $67.1 \%$ of schoolchildren neurotic frustration were marked; at 52,7\% - mood oppression; at 22,5\% - a depression; at $14,4 \%$-belly-aches; at 47,5\% - headaches; at $14,9 \%$ - aggravations of chronic diseases.

Thus, the syndrome of pedagogical violence is one of the significant factors, influencing physical and mental health of schoolboys.

\section{PO-0963 DESCRIPTIVE ANALYSIS OF READMISSIONS IN A BRAZILIAN PAEDIATRIC EMERGENCY DEPARTMENT}

L Faustino, FY Matsumoto, ACV Caluza, FG Tartuce, JL Souza, MM Menezes. Emergency Department, Hospital Israelita Albert Einstein, São Paulo, Brazil

\subsection{6/archdischild-2014-307384.1582}

Background Emergency department (ED) use has increased, resulting in overcrowding, longer wait periods and the decreased productivity of health care workers. The primary objective of this study was to describe the patients characteristics and the reasons for the readmission after an initial visit.

Methods This was a cross-sectional analysis of ED return admissions within 15 days after an initial visit, from August 1, 2013 to September 1, 2013. Patients aged 16 years or younger were enrolled in the study.

Results A total of 1418 children were seen in the ED during the study period and the return admission rate was 3.74\% $(\mathrm{n}=53)$. Patients had a mean age of 52.44 months $(52.44+43.94)$. Respiratory conditions were more likely to return (48\%), laboratory tests or X-ray were necessary in $54.9 \%$, complications due to the primary condition was present in $45.1 \%$ and $88.2 \%$ of the patients were regular followed by private doctors.

Conclusions This study suggests that readmissions are frequently, costly and contributes to emergency room crowding. Like other analyses, child's age, infection diseases and respiratory illness were the most important reasons for the readmissions. Further studies should be performed to understand this phenomenon and to test especific interventions to parental education and improvement of information system.

\section{PO-0964 TRAINING UPCOMING LEADERS IN PAEDIATRIC SCIENCE (TULIPS), A SUCCESSFUL TRAINING PROGRAM FOR CLINICAL SCIENTISTS}

${ }^{1}$ SHP Simons, ${ }^{2} \mathrm{~L}$ Haverman, ${ }^{3} \mathrm{SS}$ Henriet, ${ }^{4} \mathrm{SA}$ Fuchs. ${ }^{1}$ Neonatology, Erasmus University Medical Center - Sophia Children's Hospital, Rotterdam, Netherlands; '2Pediatric Psychology, Academic Medical Center Amsterdam -Emma Children's Hospital, Amsterdam, Netherlands; ${ }^{3}$ Pediactric Infectious Diseases, Radbout University Medical Center -Amalia Children's Hospital, Nijmegen, Netherlands; ${ }^{4}$ Pediatrics / Metabolic Disease, UMC Utrecht - Wilhelmina Children's Hospital, Utrecht, Netherlands

\subsection{6/archdischild-2014-307384.1583}

Background and aims The quality of research and collaboration between researchers within the field of child health needs to be improved. Bringing together and training young researchers has the potential to increase the quality of research and improve the care for sick children.

Methods In the Netherlands, a training program named TULIPS was set up by young scientists to stimulate other talented young researchers in paediatric science. The program aims to stimulate the research career and network of the participants to improve the quality of research and collaborations within child health.

Results During the last seven years TULIPS has organised an annual day for young investigators, grant writing and presenting weekends and bi-annual training programs for selected $\mathrm{PhD}$ students and post-doc researchers in the Netherlands. The training programs consist of interactive sessions on topics tailored to the phase in the scientific career of the participants and are hosted by experts in the field. A large network of child health researchers is part of TULIPS (197 members). The TULIPS program has been supported by numerous stakeholders, including the heads of all academic centres in the Netherlands. Scientific outcomes of the program will be evaluated by following the careers of participants after completion of the curricula.

Conclusions TULIPS has become a successful, broadly supported non-profit foundation to stimulate young clinician scientists during their careers. Extension of TULIPS across Europe would be a next step to create international networks of young researchers with the aim and potential to further improve child health. 